\title{
In Vitro Cyto-genotoxicity of Hydroxycitric Acid: A Weight-loss Dietary Supplement
}

\author{
Ilika Ghosh and Anita Mukherjee* \\ Cell Biology and Genetic Toxicology Laboratory, Centre of Advance Study, Department of Botany, University of Calcutta, Kolkata \\ 700019, India
}

\begin{abstract}
Background/Objectives: The growing issue of clinical obesity has led to increased consumption of weight-loss dietary supplements containing hydroxycitric acid (HCA) derived from the fruit rind of Garcinia cambogia, a plant widely distributed in Asia and Africa. It is often consumed in an unregulated manner, beyond the permissible dose, to achieve the target weight-loss. However, its safety/efficacy is controversial and reports on cytotoxicity and genotoxicity are limited and inconsistent. Hence, we aimed to study the putative effects of HCA on genotoxicity in human peripheral blood cells.
\end{abstract}

Methods: Human lymphocytes and erythrocytes were treated with HCA (0,10, 20, 40 or $100 \mu \mathrm{g} / \mathrm{mL})$ for $3 \mathrm{~h}$ or 24 $\mathrm{h}$ and processed for cytotoxicity and genotoxicity analyses.

Results: Initial phytochemical assessment of HCA revealed the presence of high flavonoid content. Subsequent multiendpoint cyto-genotoxicity studies in human lymphocytes displayed low cytotoxicity but significant genotoxicity at higher concentrations of 40 and $100 \mu \mathrm{g} / \mathrm{mL}$; these concentrations are approximately equivalent to and double the maximum permissible dose ( $2800 \mathrm{mg} /$ day), respectively. Flow cytometric estimation of reactive oxygen species (ROS), mitochondrial membrane potential $(\Delta \Psi \mathrm{m})$ and mode of cell death revealed significant ROS generation at the higher concentrations, but no effect on $\Delta \Psi \mathrm{m}$ and apoptosis/necrosis. Insignificant hemolysis was observed in erythrocytes.

Conclusions: High flavonoid content of HCA potentially imparts pro-oxidant property, facilitating DNA damage at high concentrations. However, such genotoxicity does not lead to cell death. Therefore, HCA can be recommended for safe consumption within the permissible dose limit.

Introduction

Obesity-a rising public health concern in all industrialized nations

Keywords: Comet assay; DNA diffusion; ROS; Mitochondrial membrane potential; Apoptosis; Hydroxycitric acid.

Abbreviations: HCA, hydroxycitric acid; ROS, reactive oxygen species; $\Delta \Psi \mathrm{m}$, mitochondrial membrane potential; ATP, adenosine triphosphate; TB test, trypan blue dye exclusion test; MTT, 3-(4,5-dimethythiazol- 2-yl)-2,5-diphenyl tetrazolium bromide; TPC, total phenolic content; TFC, total flavonoid content; OECD, Organisation for economic co-operation and development; MMS, methylmethanesulfonate; PI, propidium iodide; DCFH-DA, 2', 7'dichlorofluorescein diacetate; FITC, fluorescein isothiocyanate.

Received: January 17, 2017; Revised: March 24, 2017; Accepted: April 18, 2017

*Correspondence to: Anita Mukherjee, Cell Biology and Genetic Toxicology Laboratory, Centre of Advance Study, Department of Botany, University of Calcutta, 35 Ballygunge Circular Road Kolkata 700019, India. Tel.: +91 9831061998; Fax: +91 033 24614849, E-mail: anitamukherjee28@gmail.com

How to cite this article: Ghosh I, Mukherjee A. In Vitro Cyto-genotoxicity of Hydroxycitric Acid: A Weight-loss Dietary Supplement. J Explor Res Pharmacol 2017;2(2):4148. doi: 10.14218/JERP.2017.00003. of the world-is often designated as an epidemic, affecting about 600 million adults worldwide and with an annual death toll of 300,000 in South-East Asia. ${ }^{1}$ As a result, consumption of alternative anti-obesity medications has gained popularity. Among them, weight-loss dietary supplements containing hydroxycitric acid (HCA), derived from the dried fruit rind of Garcinia sp. (16-26\% HCA), include a major fraction, with a permissible dose of 15-47 $\mathrm{mg} / \mathrm{kg} /$ day $(900 \sim 2800 \mathrm{mg} /$ day for a person weighing $60 \mathrm{~kg}){ }^{2} \mathrm{Nev}-$ ertheless, clinically obese patients have the propensity to consume unregulated doses in order to achieve their target weight. The fruit of Garcinia sp. is used in traditional Chinese medicine for its antioxidant properties, which can be partly attributed to the presence of HCA. $^{3,4}$ It performs competitive inhibition of ATP citrate lyase, an extra- mitochondrial enzyme which catalyzes the formation of the primary building blocks of fatty acid and cholesterol biosynthesis, oxaloacetate and acetyl coenzyme A from citrate coenzyme A. ${ }^{5}$

Cyto-genotoxicity studies on HCA are limited and their results are often conflicting, since different investigators have used different production processes, concentrations, Garcinia sp. and sampling points; the contradictions may also be due to the structural 
<smiles>O=C(O)CC(O)(C(=O)O)C(O)C(=O)O</smiles>

\section{Fig. 1. Chemical structure of hydroxycitric acid.}

instability of HCA, as it alters from open chain to lactone form, which is stabilized by counter ions such as potassium or calcium. ${ }^{5}$ In vivo genotoxicity studies have revealed the induction of chromosome aberration (CA), sister chromatid exchange (SCE) and micronuclei (MN) ${ }^{6,7}$ Paradoxically, recent in vitro studies did not reveal genotoxicity but showed cytotoxicity. 8,9

Thus, in view of the recent incongruent scientific findings and the rising demand for HCA, the present study was undertaken using multiple cytotoxic (trypan blue dye exclusion (TB) test and MTT assay), genotoxic (comet, DNA diffusion assays) endpoints for the first time, with emphasis on their mechanisms by detection of reactive oxygen species (ROS) generation (to reflect genotoxicity), mitochondrial membrane potential (signified by $\Delta \Psi \mathrm{m}$ ) and apoptosis/ necrosis (to reflect cytotoxicity) in human lymphocytes. The hemolytic effect of HCA in erythrocytes was also assessed. The assays for total polyphenolic content (TPC) and total flavonoid content (TFC) were employed for an initial phytochemical analysis. HCA showed high TFC, absence of cytotoxicity and hemolysis, but induced genotoxicity at concentrations higher than that recommended daily.

\section{Methods}

\section{Test substance}

Calcium salt of HCA (extracted from the fruit rind of Garcinia cambogia) was procured from Arjuna Natural Extracts Limited (Kerala, India) (Product code: GCC-073; CAS No. 90045-23-1). Figure 1 represents the chemical structure of HCA. The percentage of HCA was $50.9 \%$ (by high-performance liquid chromatography), with calcium content of $13-19 \%$ and salt content of $<2.5 \%$, as provided by the manufacturer. The lactone and citric acid contents were $1.2 \%$ and $3.1 \%$, respectively. ${ }^{10}$ This compound containing $\sim 50 \%$ HCA was used for toxicity studies without further purification, as it is consumed in its crude form.

\section{Phytochemical analysis}

Ethanolic extracts of $\mathrm{HCA}(5,7.5$ and $10 \mathrm{mg} / \mathrm{mL})$ were used for phytochemical screening.TPC was estimated according to the method of Singleton et al. ${ }^{11}$ using gallic acid as the standard. For TFC, the method of Chang et al. ${ }^{12}$ was used with the minor modifications described by Nag et al. ${ }^{13}$ with quercetin as the standard. TPC was measured spectrophotometrically (Beckman Coulter, CA, USA) at $765 \mathrm{~nm}$ and expressed in terms of $\mathrm{mg}$ gallic acid equivalent per g HCA extract (mg GAE/g). TFC was estimated at $420 \mathrm{~nm}$ (Beckman Coulter) and calculated as mg quercetin equivalent per g HCA extract (mg QUE/g). All experiments were performed in triplicate.

\section{Test systems and treatment}

Human blood was drawn by venipuncture from 3 healthy male adult volunteers (non-smokers, non-alcoholics and not consuming any medication), with their consent and following the Organisation for Economic Co-operation and Development (OECD) guidelines. ${ }^{14}$ Lymphocytes from each donor were isolated separately following the method of Boyum, ${ }^{15}$ using Histopaque density gradient followed by resuspension in RPMI-1640 media at a concentration of $2 \times 10^{6}$ cells $/ \mathrm{mL}$. Cell populations with $>98 \%$ viability, as determined by TB test, were used. ${ }^{16}$ Erythrocytes were separated as previously described by Ghosh et al. ${ }^{17}$ and diluted in phosphatebuffered saline (PBS) to a concentration of $2 \times 10^{6}$ cells $/ \mathrm{mL}$.

Selection of the concentration of HCA for study was based on preliminary cytotoxicity tests, previously published literature and recommended daily dosage. ${ }^{2}$ Cytotoxicity analysis was performed using MTT assay in concentrations ranging from $0-200 \mu \mathrm{g} / \mathrm{mL}$ HCA, where the cut-off point was deemed to be $70 \%$ cell viability as reported by Henderson et al. ${ }^{18}$ The freshly isolated lymphocytes and erythrocytes were incubated with $0,10,20,40$ or $100 \mu \mathrm{g} /$ mL HCA in RPMI-1640 media, along with positive control compounds $\left(100 \mu \mathrm{M} \mathrm{H}_{2} \mathrm{O}_{2}\right.$ for TB, MTT, $\Delta \Psi \mathrm{m}$, apoptosis/necrosis, ROS assays; $100 \mu \mathrm{M}$ methylmethanesulfonate (MMS) for comet and DNA diffusion assays; and $1 \%$ TritonX-100 for hemolysis test(data not shown)) at a density of $1 \times 10^{6}$ cells $/ \mathrm{mL}$ per concentration, with exposure for $3 \mathrm{~h}$ or $24 \mathrm{~h}$ at $37^{\circ} \mathrm{C}$.

All experiments were approved with ethical clearance by the Research Ethics Committee of University of Calcutta, India. The cells were treated with each concentration of HCA separately for each donor without pooling. To achieve acceptable results, all experiments were repeated thrice from blood collected from each donor and each of the treatment concentrations were analyzed in triplicate.

\section{Cytotoxicity analyses}

TB test and MTT assay were performed according to the methods of Tennant and Mosmann, respectively, with modifications. ${ }^{16,19,20}$ In the TB test, cell viability was scored using a Neubauer hemocytometer under a light microscope (Leica, Wetzlar, Germany). For MTT, the optical density (OD) values were read (iMark ${ }^{\mathrm{TM}}$ Microplate Absorbance Reader; Bio-Rad, CA, USA) at $570 \mathrm{~nm}$, with 630 $\mathrm{nm}$ as reference wavelength.

For $\Delta \Psi \mathrm{m}$, the cells were washed in PBS, stained with rhodamine $123(10 \mu \mathrm{M}$ in PBS $)$ and incubated for $15 \mathrm{~min}$ at $37^{\circ} \mathrm{C}$ in the dark. ${ }^{17,21}$ Apoptotic and necrotic cell death was quantified using the annexin V-FITC/PI staining method by an apoptosis/ necrosis detection kit (BD Pharmingen, CA, USA). ${ }^{20,22}$ The cells were washed with PBS, resuspended in calcium binding buffer $(100 \mu \mathrm{L})$, stained with annexin V-FITC $(5 \mu \mathrm{L})$ and propidium iodide (PI) $(5 \mu \mathrm{L} ; 1 \mu \mathrm{g} / \mathrm{mL})$ for $15 \mathrm{~min}$ in the dark. Approximately 10,000 events were analyzed for both $\Delta \Psi \mathrm{m}$ and apoptosis/necrosis by flow cytometry (BD FACS Verse ${ }^{\mathrm{TM}}$; Becton Dickinson, NJ, USA). Data analysis was carried out using the BD FAC Suite software, version 1.0.5.3841 (Becton Dickinson). The percentages of viable $\left(\mathrm{PI}^{-}\right.$, annexin $\mathrm{V}^{-}$), early apoptotic (annexin $\left.\mathrm{V}^{+}, \mathrm{PI}^{-}\right)$, late apoptotic (annexin $\mathrm{V}^{+}, \mathrm{PI}^{+}$) and necrotic (annexinV ${ }^{-}, \mathrm{PI}^{+}$) cells were calculated. The results of $\Delta \Psi \mathrm{m}$ were expressed as foldchange over control.

\section{Genotoxicity analysis}

Comet assay was performed following the method of Tice et $a l .{ }^{23}$, with modifications. ${ }^{20}$ Slides were prepared in triplicate per concentration;image procurement (Leica) and data analysis 


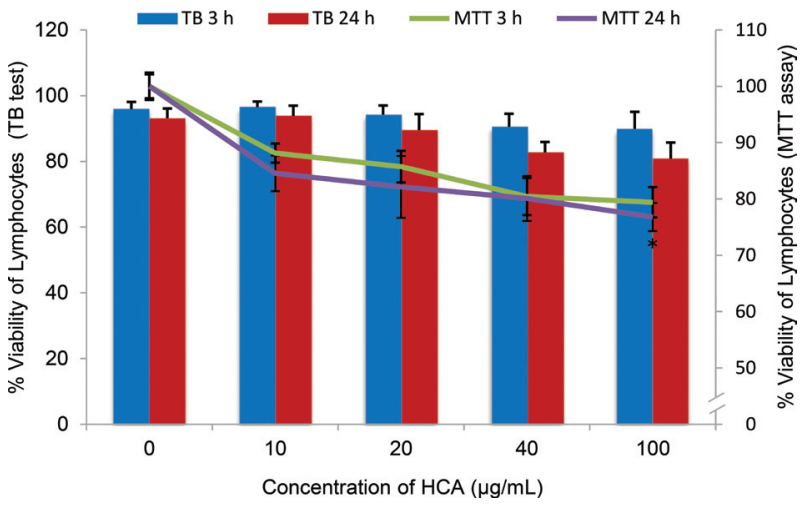

Fig. 2. Cytotoxicity evaluation of HCA at $0,10,20,40$ and $100 \mu \mathrm{g} / \mathrm{mL}$ in human lymphocytes after $\mathbf{3} \mathrm{h}$ and $\mathbf{2 4} \mathrm{h}$ by trypan blue dye exclusion test and MTT assay. ${ }^{*} p<0.05$ vs. control, one-way ANOVA, $n=3$. Abbreviations: HCA, hydroxycitric acid; TB test, trypan blue dye exclusion test; MTT, 3-(4,5-dimethythiazol- 2-yl)-2,5-diphenyl tetrazolium bromide.

were carried out using Komet 5.5 software (Kinetic Imaging, Nottingham, UK). Among the comet parameters, we report the medians of the percent tail DNA from $300(100 \times 3)$ nuclei/concentration. The number of hedgehog structures were counted manually (300 nuclei/concentration; 100/slide) and expressed as percent. ${ }^{24}$

DNA diffusion assay was performed according to the method of Gichner et al. ${ }^{25}$, with modifications. ${ }^{20}$ Slide processing was the same as for the comet assay, but without subjectionto electrophoresis. The slides were placed in spermine solution $(1 \mathrm{mg} / \mathrm{mL}$ in $50 \%$ ethanol) for $30 \mathrm{~min}$ after lysing. Staining, visualization and data analysis was the same as in the comet assay. The percentage of nuclear area of $300(100 \times 3)$ nuclei per concentration was used to express nuclear DNA diffusion and the percentage of diffused nuclei was calculated manually.

The treated lymphocytes were incubated in $2^{\prime}, 7^{\prime}$ dichlorofluorescein diacetate (DCFH-DA) $(25 \mu \mathrm{M}$ in PBS) for $30 \mathrm{~min}$ at 37 ${ }^{\circ} \mathrm{C}$ in the dark for ROS analysis. ${ }^{17,26}$ About 10,000 events were analyzed by flow cytometer using the same instrument and data analysis software as for the study of $\Delta \Psi \mathrm{m}$ and apoptosis/necrosis. Data are expressed as fold-change over control.

\section{Effect on erythrocytes by hemolysis test}

The treated erythrocyte suspensions were analyzed for hemolysis according to the method of Katsu et al. ${ }^{27}$, with modifications. ${ }^{17}$ The degree of hemolysis was estimated by measuring the absorbance of the supernatant at $540 \mathrm{~nm}$ (Beckman Coulter). Results are expressed as:

$$
\% \text { hemolysis }=\left[\frac{a-b}{c-b}\right] \times 100
$$

Where $a=$ Absorbance $_{\text {Sample }}, b=$ Absorbance $_{\text {Negative control, }}$, and $c=$ Absorbance $_{\text {Positive control }}$

\section{Statistical analysis}

One-way ANOVA (Sigma Plot 12.0, Systat Software Inc., CA, USA) was performed and the level of statistical significance was established at $p<0.05$. Multiple comparisons were carried out us- ing Duncan's multiple range tests. All data are presented as mean \pm SEM of three replicates.

Results

\section{Phytochemical analysis of $\mathrm{HCA}$}

TPC and TFC of HCA were assessed for phytochemical analysis. TPC was estimated to be $0.105 \pm 0.022 \mathrm{mg} \mathrm{GAE} / \mathrm{g}$, as determined by reference to the standard curve of gallic acid $(\mathrm{y}=0.088 \mathrm{x}+$ $\left.0.132, \mathrm{R}^{2}=0.99\right)$. A high TFC of $8.94 \pm 0.082 \mathrm{mg}$ QUE/g was detected, by reference to the standard curve of quercetin $(\mathrm{y}=0.037 \mathrm{x}$ $+0.0017, \mathrm{R}^{2}=0.99$ ).

\section{Effect of HCA on cell viability, mitochondrial function and mode of cell death in human lymphocytes}

Figure 2 demonstrates the absence of significant induction of cytotoxicity, as evaluated by TB test and MTT assay. No significant decline in cell viability was observed by TB test at either time interval $(p<0.05)$, demonstrating lack of effect on cell membrane permeability. Exposure to the highest concentration of HCA $(100 \mu \mathrm{g} / \mathrm{mL})$ led to $89.88 \%$ and $80.83 \%$ cell viability at $3 \mathrm{~h}$ and $24 \mathrm{~h}$, respectively. The percent cell viability with the positive control $\mathrm{H}_{2} \mathrm{O}_{2}(100 \mu \mathrm{M})$ was $81.7 \%$ and $73.2 \%$ at $3 \mathrm{~h}$ and $24 \mathrm{~h}$, respectively. MTT assay displayed no significant decline in cell viability, indicating no effect on the mitochondrial dehydrogenase activity after $3 \mathrm{~h}$ and $24 \mathrm{~h}$, with the exception of a significant decline $(76.79 \%)$ at the highest concentration of $100 \mu \mathrm{g} / \mathrm{mL}$ at $24 \mathrm{~h}$ (Fig. 2). $\mathrm{IC}_{50}$ values of HCA ranged from $29.330 \pm 0.072 \mathrm{mg} / \mathrm{mL}$ at $3 \mathrm{~h}$ to $27.695 \pm 0.069 \mathrm{mg} / \mathrm{mL}$ at 24 h exposure. The positive control $\mathrm{H}_{2} \mathrm{O}_{2}(100 \mu \mathrm{M})$ revealed percent cell viability of $69.41 \%$ and $56.69 \%$ at $3 \mathrm{~h}$ and $24 \mathrm{~h}$, respectively.

The cationic fluorescent probe rhodamine 123 revealed insignificant depolarization of the mitochondrial membranes $(\Delta \Psi \mathrm{m})$ upon HCA treatment at both time points (Fig. 3). The least decline in the intensity of rhodamine 123 fluorescence quantified at $24 \mathrm{~h}$ was $\sim 21 \%$ less than control in $100 \mu \mathrm{g} / \mathrm{mL}$ HCA-treated cells.

The mode of cell death was assessed by annexin V-FITC/PI double-staining. There was insignificant rise in early or late apoptotic cells and negligible occurrence of necrotic cells at all treatment concentrations (Fig. 4). These results mirror the MTT assay data. Thus, the unaffected mitochondrial dehydrogenase activity, unaltered mitochondrial metabolic activity and the retention of intact mitochondrial membranes are correlated with the absence of apoptosis. The meager frequency of necrotic cells can be corroborated with the TB test data showing lack of cell membrane damage.

\section{Evaluation of genotoxicity and oxidative stress in human lym- phocytes}

HCA-induced DNA damage (tail DNA percent) was statistically significant at concentrations of 40 and $100 \mu \mathrm{g} / \mathrm{mL}$, at both time points,as observed by comet assay. The percent tail DNA values were approximately 6- and 7-fold higher than the respective controls at $100 \mu \mathrm{g} / \mathrm{mL}$ after $3 \mathrm{~h}$ and $24 \mathrm{~h}$, respectively (Fig. 5a). These concentrations are almost identical to and approximately double the maximum permitted dose (i.e. $900-2800 \mathrm{mg} /$ day or $15-47 \mathrm{mg}$ / $\mathrm{kg} /$ day, respectively). ${ }^{2}$ The percent increase in hedgehogs followed a similar pattern as the comet results $(p<0.05)$. The positive control MMS $(100 \mu \mathrm{M})$ showed $62.9 \%$ and $76.42 \%$ tail DNA and led 
A

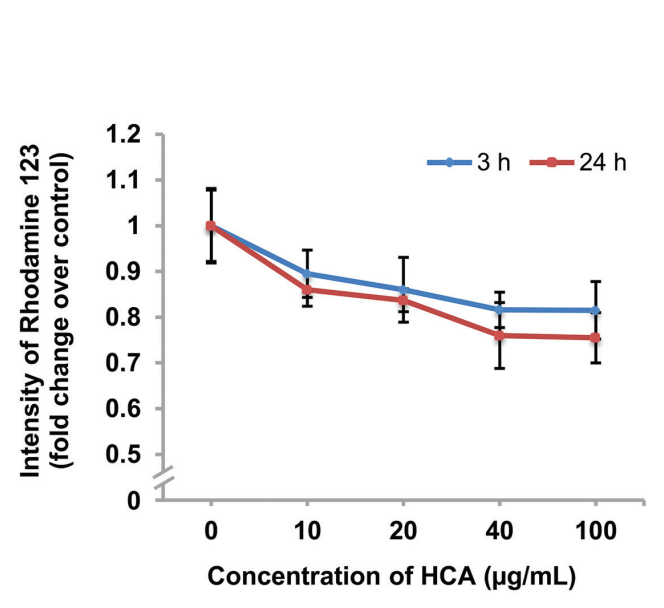

B
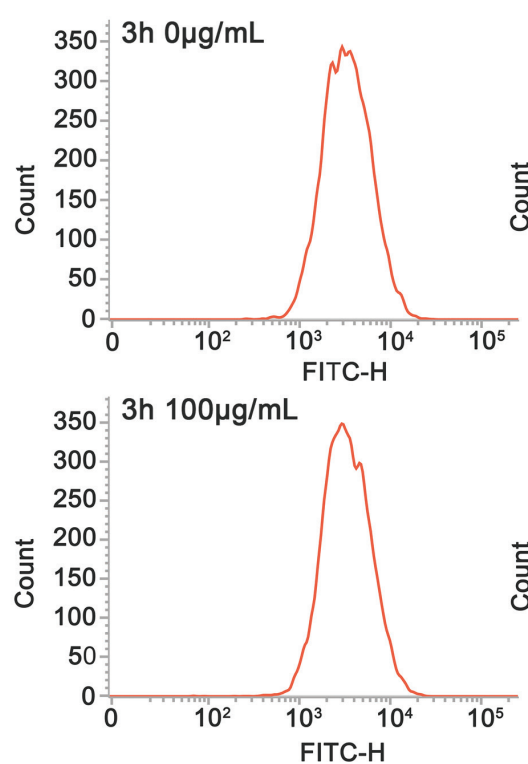
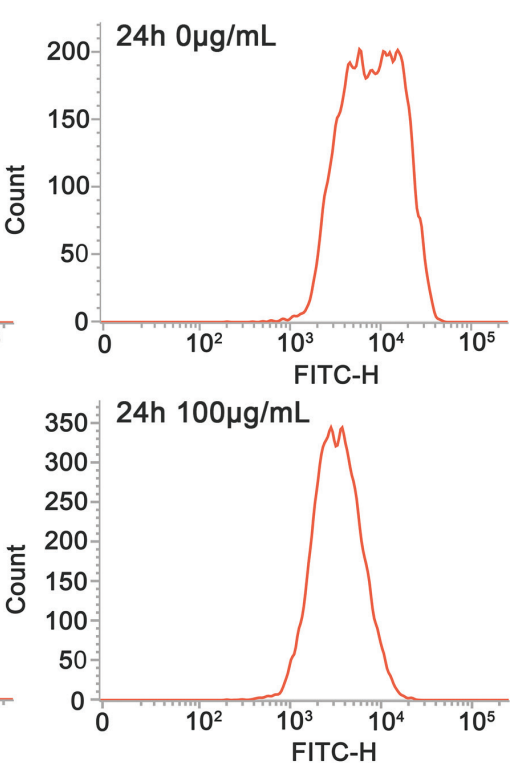

Fig. 3. Flow cytometric estimation of mitochondrial membrane potential by rhodamine 123 staining in human lymphocytes treated with various concentrations of HCA for $\mathbf{3} \mathbf{~ h}$ and $\mathbf{2 4} \mathbf{~ h}$. (a) Intensity of rhodamine 123 fluorescence as fold-change over control. (b) Representative flow cytometry histograms of control and the highest treatment concentration of HCA $(100 \mu \mathrm{g} / \mathrm{mL})$ at $3 \mathrm{~h}$ and $24 \mathrm{~h}$ time intervals. ${ }^{*} p<0.05$ vs. control, one-way ANOVA, $n=3$. Abbreviations: HCA, hydroxycitric acid; FITC, fluorescein isothiocyanate.

to the formation of $37.2 \%$ and $52.4 \%$ hedgehogs, after $3 \mathrm{~h}$ and 24 $\mathrm{h}$, respectively. DNA diffusion under alkaline/neutral conditions is a widely-accepted biomarker of DNA strand breaks that lead to apoptotic/necrotic cell death. ${ }^{24}$ Figure 5 b shows the minor rise in the percent nuclear area and frequency of diffused nuclei upon HCA treatment, which is indicative of low cytotoxicity. The highest treatment concentration of HCA $(100 \mu \mathrm{g} / \mathrm{mL})$ induced significant increase in the percent nuclear area at $3 \mathrm{~h}$ and $24 \mathrm{~h}$ compared to the respective controls. MMS $(100 \mu \mathrm{M})$ induced substantially high increase in the percent nuclear area and the percent diffused nuclei at $3 \mathrm{~h}$ and $24 \mathrm{~h}$.

As a mechanism of DNA damage, oxidative stress was evaluated using the hydrophobic non-fluorescent dye DCFH-DA, which infiltrates cells rapidly and is hydrolyzed by intracellular esterases to produce DCFH. The oxidation of DCFH by intracellular ROS to its fluorescent 2-electron product 2', 7'dichlorofluorescein (DCF) was quantified by flow cytometry. Significant increase in ROS production was found at concentrations of $40 \mu \mathrm{g} / \mathrm{mL}$ and above at both the $3 \mathrm{~h}$ and $24 \mathrm{~h}$ times compared to the respective controls (Fig. 6). The results were approximately 2- and 3-fold higher for $100 \mu \mathrm{g} / \mathrm{mL}$ of HCA exposure than that of control at $3 \mathrm{~h}$ and $24 \mathrm{~h}$, respectively.

Taken together, the results suggest that HCA-induced genotoxicity may not lead to apoptotic/necrotic cell death. Such DNA damage can be attributed to oxidative stress, which is independent of mitochondrial ROS generation, as reflected by negligible decline in $\Delta \Psi \mathrm{m}$.

\section{Estimation of hemolytic potential}

Toxicity studies on lymphocytes were succeeded by an analysis of the hemolytic potential of erythrocytes. As shown in Figure 7, there was no significant rise in percent hemolysis at either $3 \mathrm{~h}$ or
24 h compared to control.

Discussion

The rising problem of clinical obesity has led to the increased usage of HCA derived from Garcinia sp. as the chief component of weight-loss dietary supplements, thereby necessitating its thorough toxicological evaluation. Reports on its safety and efficacy are conflicting, and the published in vitro studies using cyto-genotoxic endpoints are limited. Therefore, the present investigation was carried out using human lymphocytes and erythrocytes to provide information on (a) cytotoxicity and mitochondrial function, (b) genotoxicity and oxidative stress, and (c) hemolysis induced by HCA.

Phytochemical screening of HCA in terms of TPC and TFC was undertaken to understand the correlation between its chemical constituents and their biological effects in vitro. The TFC (8.94 $\pm 0.082 \mathrm{mg}$ QUE$/ \mathrm{g})$ of HCA was higher than the TPC $(0.105 \pm$ $0.022 \mathrm{mg} \mathrm{GAE} / \mathrm{g}$ ). Present literature is replete with diverse values of TPC and TFC which vary with extraction solvents (ethanol, methanol, water) and Garcinia species. ${ }^{3,4}$ High flavonoid content of $G$. cambogia fruit extracts (ethanolic/methanolic and water) ranges between $0.137-30 \mathrm{mg}$ QUE/g. ${ }^{3,4}$ Our result of high TFC for pure Ca salt of HCA derived from G. cambogia fruit rind is within the range of these available values for crude G. cambogia extracts. Such high TFC of HCA is also validated by previous studies and is reported to cause hypolipidemic activity. ${ }^{28}$

In our study, HCA was non-cytotoxic to human lymphocytes, as demonstrated by TB test and MTT assay,and showed negligible mitochondrial dysfunction at the tested concentrations. Findings reported from elsewhere have indicated that G. atroviridis acid ester derivatives containing HCA were non-cytotoxic in CEMSS (human T-lymphoblastic leukemia) cells and Raji (human B-lymphoblastoid) cells. ${ }^{29}$ On the other hand, exposure of 3T3 fibroblast 
A 3 h
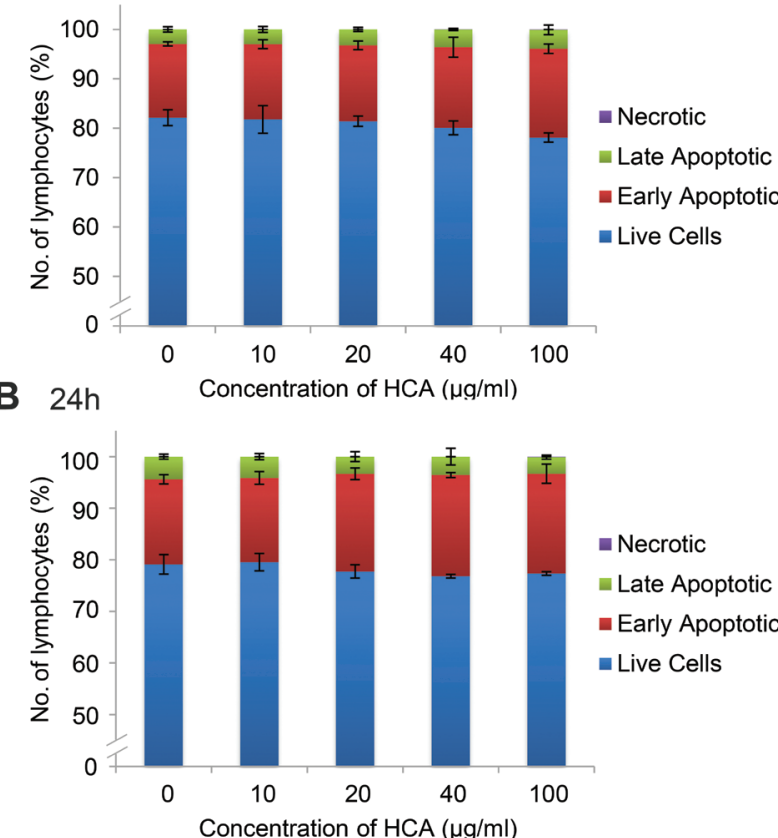

C
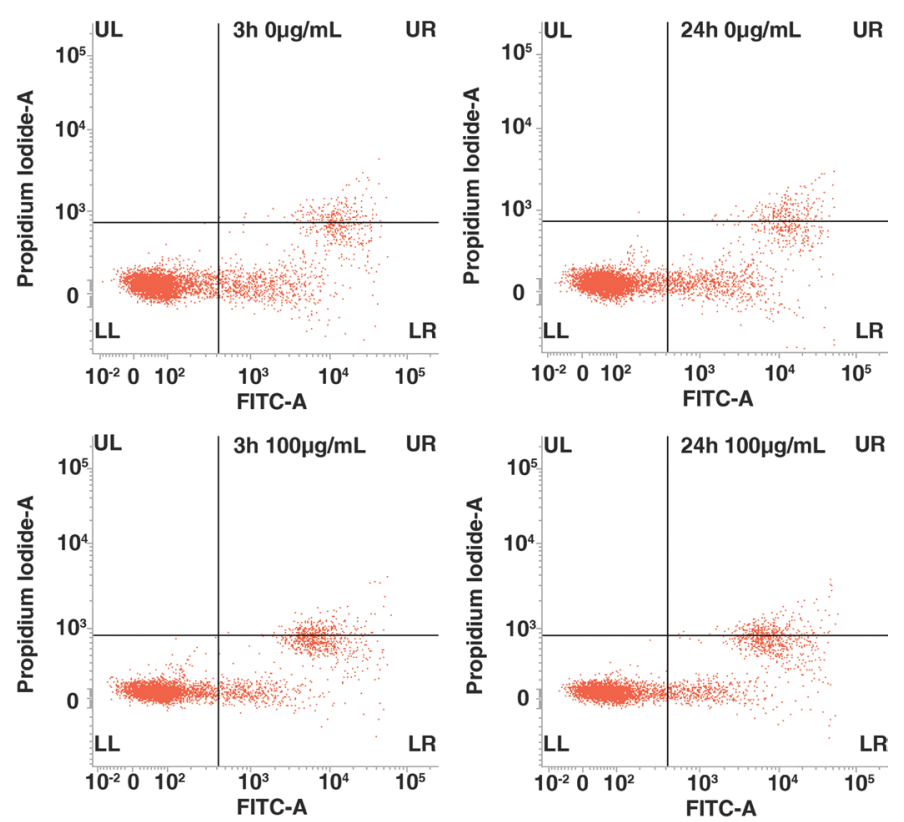

Fig. 4. Mode of cell death assessed by annexin V/FITC-PI staining in human lymphocytes treated with $0,10,20,40$ and $100 \mu \mathrm{g} / \mathrm{mL} \mathrm{HCA}$ after $3 \mathrm{~h}$ and $24 \mathrm{~h}$. Frequency of live, early apoptotic, late apoptotic and necrotic lymphocytes after (a) $3 \mathrm{~h}$ and (b) $24 \mathrm{~h}$. (c) Representative flow cytometry dot plots showing the distribution of events according to the intensity of FITC and propidium iodide scattering among the quadrants segregated as LL (live cells), LR (early apoptotic cells), UR (late apoptotic cells) and UL (necrotic cells) at control and the highest HCA concentration $(100 \mu \mathrm{g} / \mathrm{mL}) .{ }^{*} p<0.05 \mathrm{vs}$. control, one-way ANOVA, $n=3$. Abbreviations: HCA, hydroxycitric acid; FITC, fluorescein isothiocyanate.

cells to G. indica crude extracts diluted in dimethyl sulfoxide at a concentration of $240 \mu \mathrm{g} / \mathrm{mLled}$ to nearly $80 \%$ decline in cell viability after 6 days. ${ }^{9}$ Such divergent results may be due to differences in treatment duration, test system, type of extracts and dilution solvent. Therefore, we considered it prudent to evaluate the mechanisms of induced cytotoxicity with regard to mitochondrial membrane potential and mode of cell death by flow cytometry.

Alteration in mitochondrial membrane potential (as signified by $\Delta \Psi \mathrm{m})$ as a result of mitochondrial dysfunction and subsequent apoptosis is a key mechanism of cytotoxicity. ${ }^{21}$ The effect of HCA on mitochondrial function was negligible, as observed by the uptake of the positively-charged fluorescent dye rhodamine-123 by mitochondrial membranes of the treated lymphocytes. These results are congruent with the findings of MTT assay and the mode of cell death analyzed by annexin V-FITC/PI double-staining. Hence, we provide the first report of Ca salt of HCA derived from G. cambogia being non-cytotoxic to human lymphocytes.

HCA-induced genotoxicity was significant at high concentrations (40 and $100 \mu \mathrm{g} / \mathrm{mL}$ ) for both time intervals examined. Importantly, these concentrations are nearly equivalent to and higher than the permissible dose (i.e. $2800 \mathrm{mg}$ /day), respectively. ${ }^{2}$ The rise in hedgehog frequency and nuclear area validated the increase in percent tail DNA by comet assay, although such DNA strand breaks did not culminate in apoptosis/necrosis. In this regard, it can be assumed that repair enzymes may be involved to prevent the onset of cytotoxicity as a result of a continuous process of DNA damage.

Hedgehogs are comet structures with pin-like heads and nearly all DNA concentrated in the tail. Recent reports have affirmed the occurrence of hedgehogs as an upper end of a continuous process of DNA damage and not diagnostic of apoptosis/cytotoxicity, as previously believed. ${ }^{24}$ Hence, DNA diffusion assay was used in this study to distinguish apoptotic nuclei having dense central nuclear DNA with a hazy and lighter halo-like outer zone from necrotic nuclei with well-defined outer boundary and relatively distinct appearance. ${ }^{25}$ Among the diffused nuclei, we observed apoptotic nuclei rather than necrotic nuclei. This is in agreement with the negative finding of necrotic cells by TB test and the annexin VFITC/PI double-staining data showing minor but insignificant rise in early apoptotic cells and negligible necrotic cell populations.

Our group recently affirmed the DNA damaging potential of $G$. indica fruit extracts in mice by the cytogenetic endpoints of SCE and CA. ${ }^{6}$ Lee and Lee, ${ }^{7}$ reported significant induction of MN at higher concentrations of HCA-SX $(\mathrm{Ca} / \mathrm{K}$ salt of $60 \% \mathrm{HCA})$ in mice. ${ }^{7}$ In particular, chromosome aberration tests performed in Chinese hamster ovary cells exposed to HCA-SX revealed absence of chromosome aberrations. ${ }^{7}$ In another study, comet assay of human blood treated for $4 \mathrm{~h}$ with crude $G$. cambogia extracts (at 125 and $250 \mu \mathrm{g} / \mathrm{mL}$ concentrations) showed a steady but statistically insignificant rise in DNA damage. ${ }^{8}$ Furthermore, in vivo cytogenetic studies and in vitro bacterial mutagenicity analyses were negative for citric acid and its sodium and tripotassium salts present in HCA formulations, proving HCA to be the chief cause of genotoxic responses. ${ }^{30}$

These contrasting genotoxicity findings in the literature lead us to hypothesize that the DNA strand breaks induced by HCA at higher concentrations may not always progress to form chromosome aberrations in vitro, but may induce $\mathrm{MN}$, chromosome aberrations and SCE in vivo. The likelihood of such DNA damages being repaired over time and not terminating into any genetic hazard cannot be ruled out. Similar flavonoid-rich phytochemicals such as curcumin from Curcuma amada rhizome and Punica granatum L. (pomegranate) whole fruit extracts have been reported to be non- 
A

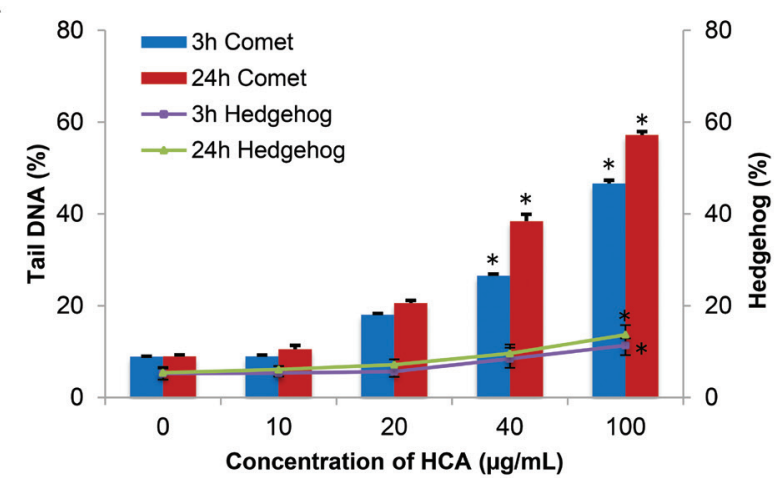

$0 \mu \mathrm{g} / \mathrm{mL} \quad 10 \mu \mathrm{g} / \mathrm{mL} \quad 20 \mu \mathrm{g} / \mathrm{mL} \quad 40 \mu \mathrm{g} / \mathrm{mL} 100 \mu \mathrm{g} / \mathrm{mL}$

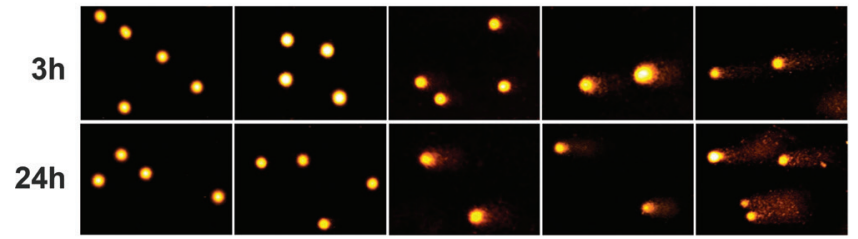

B

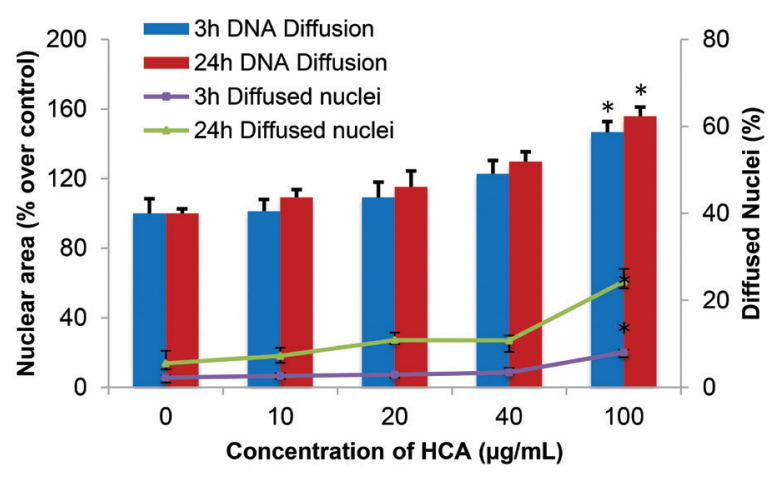

$0 \mu \mathrm{g} / \mathrm{mL} \quad 10 \mu \mathrm{g} / \mathrm{mL} \quad 20 \mu \mathrm{g} / \mathrm{mL} \quad 40 \mu \mathrm{g} / \mathrm{mL} \quad 100 \mu \mathrm{g} / \mathrm{mL}$

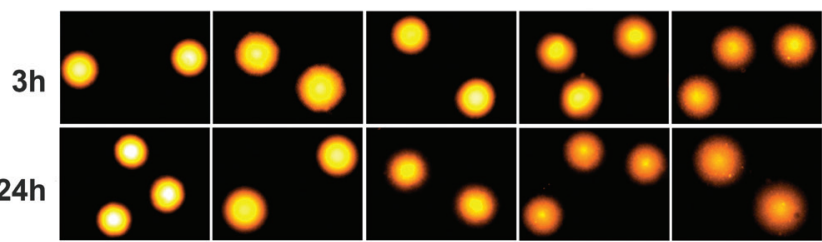

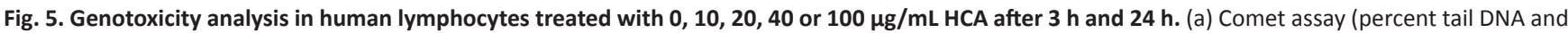
percent hedgehogs). (b) DNA diffusion assay (percent nuclear area and percent diffused nuclei). ${ }^{*} p<0.05$ vs. control, by one-way ANOVA, $n=3$. Abbreviations: HCA, hydroxycitric acid.

cytotoxic but genotoxic at higher concentrations both in vitro and in vivo. ${ }^{31,32}$

Oxidative stress is a known mechanism of DNA damage. ${ }^{17,20}$ Therefore, estimation of ROS in human lymphocytes was carried out in this study to investigate the mechanism of the genotoxic responses observed in comet assay. A significant increase in ROS was noted at the similar higher concentrations that showed genotoxic response. In this regard, studies on the potential toxicity of plant extracts rich in flavonoids by others have affirmed their prooxidant activities and possible genotoxic responses at higher concentrations. ${ }^{33}$ Thus, high TFC of HCA can be a probable cause of ROS generation at higher concentrations.

Minimal decline in $\Delta \Psi \mathrm{m}$ and subsequent low cytotoxicity implies the ability of intracellular antioxidant systems to regulate ROS levels lower than the minimum threshold limits necessary for cell injury/death. This also leads to the assumption of possible in-
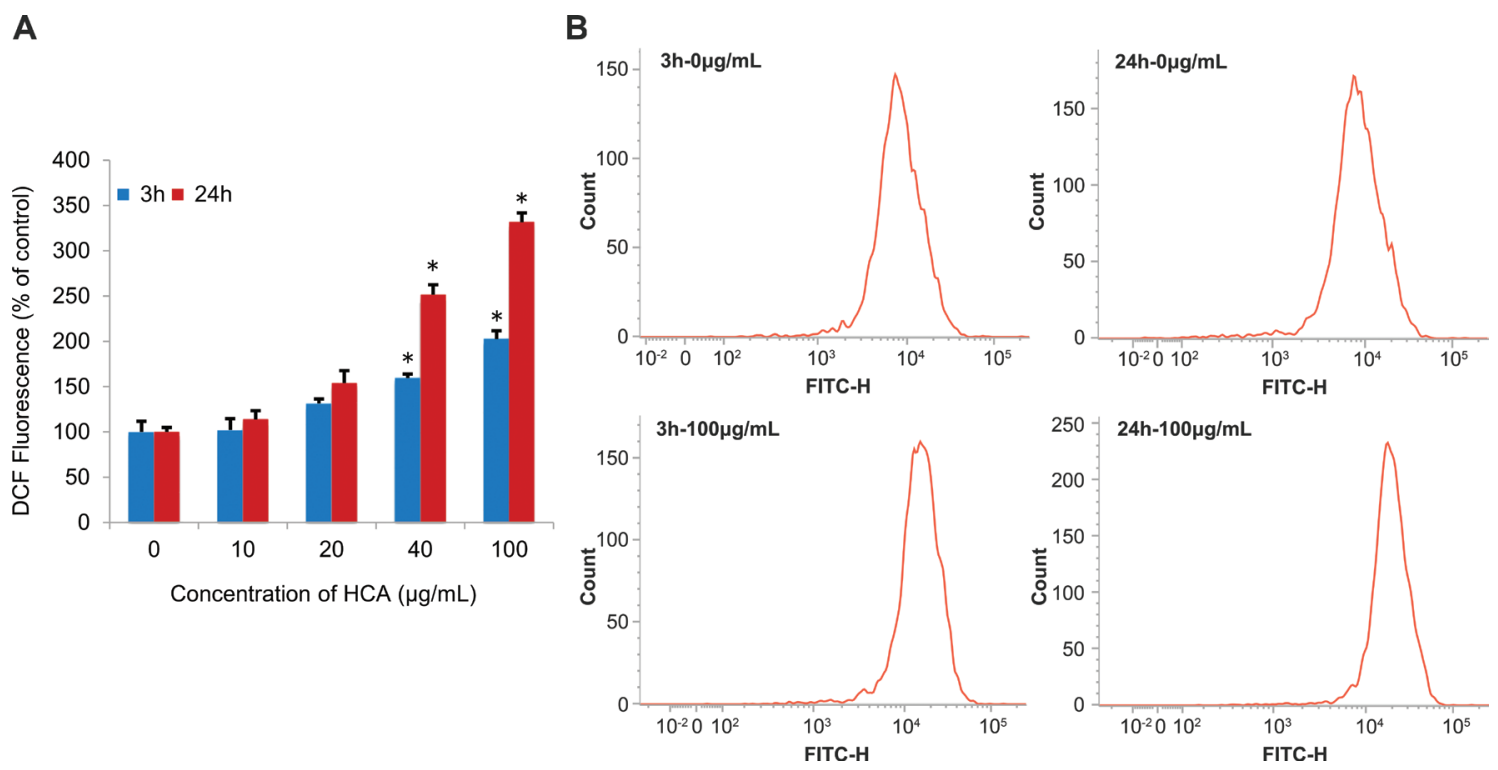

Fig. 6. Dose-dependent induction of ROS generation in human lymphocytes treated with 0, 10, 20, $40 \mathrm{or} 100 \mu \mathrm{g} / \mathrm{mL} \mathrm{HCA} \mathrm{for} 3 \mathrm{~h}$ and $24 \mathrm{~h}$. (a) Fold-change of 2', 7'dichlorofluorescein fluorescence over control. (b) Representative flow cytometry histograms of the treated lymphocytes at control and the highest HCA concentration $(100 \mu \mathrm{g} / \mathrm{mL})$ after $3 \mathrm{~h}$ and $24 \mathrm{~h} .{ }^{*} p<0.05$ vs. control, by one-way ANOVA, $n=3$. Abbreviations: HCA, hydroxycitric acid; ROS, reactive oxygen species; FITC, fluorescein isothiocyanate. 


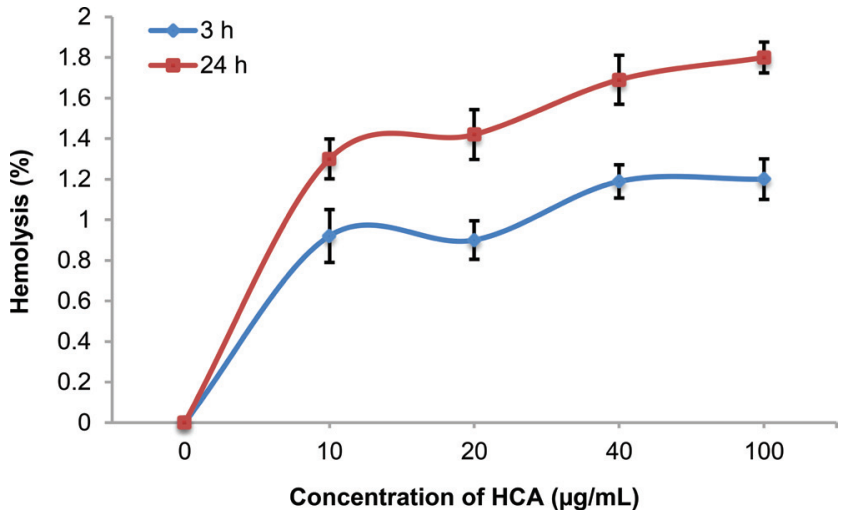

Fig. 7. Hemolytic effect of HCA on human erythrocytes. Data are presented as percent hemolysis. Abbreviations: HCA, hydroxycitric acid.

volvement of other known cellular organelles such as endosomes, lysosomes and Golgi apparatus, instead of mitochondria, in the generation of ROS. ${ }^{34,35}$ Therefore, DNA damage incited by HCA at high concentrations is ROS mediated and may be, putatively, repaired over time with the activation of cellular ROS quenching mechanisms since such genotoxic responses did not culminate in cell death. Further studies involving prolonged exposure are required to affirm such a premise.

In agreement with our findings in lymphocytes, HCA did not display any hemolytic potential in erythrocytes in our study either. A previous study on G. cambogia fruit extracts also revealed absence of hemolytic activity. ${ }^{8}$ Moreover, the same extracts also showed erythropoetic activity in Wistar rats. ${ }^{36}$

Hence, additional studies are needed to assess the DNA damage and repair pathways associated with HCA exposure at high concentrations. Moreover, our results ascertain the safe consumption of HCA within the acceptable dose limit ( $2800 \mathrm{mg} /$ day).

\section{Conclusion and future perspectives}

The findings of this study provide support for the absence of hemolysis in erythrocytes and cytotoxicity of HCA in human lymphocytes. The genotoxic potential of HCA as a result of oxidative stress was noted at tested concentrations that were high and beyond the permissible limit. Its high flavonoid content may impart pro-oxidant properties, resulting in ROS generation and leading to DNA damage. However, the possibilities of ROS quenching by the cellular antioxidant system facilitating DNA repair over time cannot be ruled out. Since our study was composed of only in vitro experiments, further studies are required to understand the DNA damage and repair mechanisms incited by HCA at different time points, both in vitro and in vivo, for its safer and more efficient long-term usage. Hence, consumption of HCA at low concentrations can be recommended for weight loss in obese and overweight individuals, with the aim of motivating them to embrace a healthier diet with regular exercise.

\section{Acknowledgments}

This work was supported by PURSE (Promotion of University Research and Scientific Excellence) program of the Department of
Science and Technology, Government of India (Sanction No. SR/ S9/Z-23/2010/15). The authors acknowledge Centre for Research in Nanoscience and Nanotechnology, University of Calcutta for providing instrumentation facilities. The Editors and Reviewers of the journal are thanked for their valuable suggestions.

\section{Conflict of interest}

The authors declare no conflicts of interest related to this publication.

\section{Author contributions}

Research design (AM), performing experiments (IG), data analysis (IG, AM), manuscript preparation (AM, IG), revision and proofreading $(\mathrm{IG}, \mathrm{AM})$.

\section{References}

[1] WHO, Overweight and obesity fact sheet. WHO Regional Office for South-East Asia (2011) http://www.searo.who.int/topics/obesity/ en/ (Accessed on 7.07.2016)

[2] Soni MG, Burdock GA, Preuss HG, Stohs SJ, Ohia SE, Bagchi D. Safety assessment of (-)-hydroxycitric acid and Super CitriMax, a nove calcium/potassium salt. Food Chem Toxicol 2004;42(9):1513-1529. doi:10.1016/j.fct.2004.04.014.

[3] Shukla A, Shukla R, Pandey V, Golhani D, Jain CP. In vitro antioxidant activity of Garcinia cambogia fruit. Journal of Medical Pharmaceutical and Allied Sciences 2014;3:67-73.

[4] Subhashini N, Nagarajan G, Kavimani S. In vitro antioxidant and anticholinesterase activities of Garcinia cambogia. Int J Pharm Pharm Sci 2011;3(3):129-132.

[5] Semwal RB, Semwal DK, Vermaak I, Viljoen A. A comprehensive scientific overview of Garcinia cambogia. Fitoterapia 2015;102:134148. doi:10.1016/j.fitote.2015.02.012.

[6] Das A, Ghosh I, Mukherjee A. Garcinia indica fruit extract induces genotoxicity in mice. Nucleus 2016;59(1):1-6. doi:10.1007/s13237015-0145-0.

[7] Lee KH, Lee BM. Evaluation of the genotoxicity of (-)-hydroxycitric acid (HCA-SX) isolated from Garcinia cambogia. J Toxicol Environ Health 2007;70(5):388-392. doi:10.1080/15287390600882192.

[8] Simao AA, Corrê AD, Preté PSC, de Rezende Queiroz E, Cesar PHS, de Moura Oliveira $\mathrm{H}$, et al. Pharmacotoxic evaluation of extracts of medicinal plants used in the treatment of obesity. Afr J Pharm Pharacol 2014;8(43):1103-1109. doi:10.5897/AJPP2014.4141.

[9] Varalakshmi KN, Sangeetha CG, Samee US, Irum G, Lakshmi H, Prachi SP. In vitro safety assessment of the effect of five medicinal plants on human peripheral lymphocytes. Trop J Pharm Res 2011;10(1):33-40. doi:10.4314/tjpr.v10i1.66539.

[10] AAntony A. Studies on hydroxycitric acid in Garcinia [Dissertation] School of Chemical Sciences, Mahatma Gandhi University, 2004, Acc No. T01237, Shodhganga: A reservoir of Indian theses @ INFLIBNET, pp. 1-168, http://hdl.handle.net/10603/6470.

[11] Singleton VL, Orthofer R, Lamuela-Raventos RM. Analysis of total phenols and other oxidation substrates and antioxidants by means of Folin-Ciocalteu reagent. Methods Enzymol 1999;299:152-178. doi:10.1016/S0076-6879(99)99017-1.

[12] Chang C, Yang M, Wen H, Chern J. Estimation of total flavonoid content in propolis by two complementary colorimetric methods. J Food Drug Analaysis 2002;10(3):178-182.

[13] Nag A, Bandyopadhyay M, Mukherjee A. Antioxidant activities and cytotoxicity of Zingiber zerumbet (L.) Smith rhizome. Journal of Pharmacognosy and Phytochemistry 2013;2(3):102-108. 
J Explor Res Pharmacol

[14] OECD. In vitro mammalian cell micronucleus test. OECD guideline for testing of chemicals section 4: Health effects. Paris: OECD Publishing. 2014:1-26, doi:10.1787/9789264224438-en.

[15] Boyum A. Isolation of lymphocytes, granulocytes and macrophages. Scand J Immunol 1976;5(Suppl 5):9-15. doi:10.1111/j.1365-3083.1976. tb02986.x.

[16] Tennant JR. Evaluation of the trypan blue technique for determination of cell viability. Transplantation 1964;2(6):685-694.

[17] Ghosh M, Chakraborty A, Mukherjee A. Cytotoxic, genotoxic and the hemolytic effect of titanium dioxide $\left(\mathrm{TiO}_{2}\right)$ nanoparticles on human erythrocyte and lymphocyte cells in vitro. J Appl Toxicol 2013;33(10):1097-1110. doi:10.1002/jat.2863.

[18] Henderson L, Jones E, Brooks T, Chételat A, Ciliutti P, Freemantle $M$, et al. Industrial genotoxicology group collaborative trial to investigate cell cycle parameters in human lymphocyte cytogenetic studies. Mutagenesis 1997;12(3):163-167.

[19] Mosmann T. Rapid colorimetric assay for cellular growth and survival: application to proliferation and cytotoxicity assays. J Immunol Methods 1983;65(1-2):55-63. doi:10.1016/0022-1759(83)903034.

[20] Sinha S, Jothiramajayam M, Ghosh M, Mukherjee A. Evaluation of toxicity of essential oils palmarosa, citronella, lemongrass and vetiver in human lymphocytes. Food Chem Toxicol 2014;68:71-77. doi:10.1016/j.fct.2014.02.036.

[21] Lopez-Mediavilla C, Orfao A, Gonzalez M, Medina JM. Identification by flow cytometry of two distinct rhodamine- 123-stained mitochondrial populations in rat liver. FEBS Lett 1989;254(1-2):115-120. doi:10.1016/0014-5793(89)81020-8.

[22] Vermes I, Haanen C, Steffens-Nakken H, Reutelingsperger C. A novel assay for apoptosis. Flow cytometric detection of phosphatidylserine expression on early apoptotic cells using fluorescein labelled Annexin V. J Immunol Methods 1995;184(1):39-51. doi:10.1016/00221759(95)00072-I.

[23] Tice RR, Agurell E, Anderson D, Burlinson B, Hartmann A, Kobayashi H, et al. Single cell gel/comet assay: guidelines for in vitro and in vivo genetic toxicology testing. Environ Mol Mutagen 2000;35(3):206-221. doi:10.1002/(SICI)1098-2280(2000)35:3<206::AID-EM8>3.0.CO;2-J.

[24] Speit G, Veseley A, Schütz P, Linsenmeyer R, Bausinger J. The low molecular weight DNA diffusion assay as an indicator of cytotoxicity for the in vitro comet assay. Mutagenesis 2014;29(4):267-277. doi:10.1093/mutage/geu015.

[25] Gichner T, Mukherjee A, Wagner ED, Plewa MJ. Evaluation of the nu-
Ghosh I. et al: Cyto-genotoxicity of hydroxycitric acid in vitro

clear DNA diffusion assay to detect apoptosis and necrosis. Mutat Res 2005;586(1):38-46. doi:10.1016/j.mrgentox.2005.05.010.

[26] Burow S, Valet G. Flow-cytometric characterization of stimulation, free radical formation, peroxidise activity and phagocytosis of human granulocytes with 2, 7-dichlorofluorescin (DCF). Eur J Cell Biol 1987;43(1):128-133.

[27] Katsu T, Kuroko M, Morikawa T. Mechanism of membrane damage induced by the amphipatic peptides gramicidin $\mathrm{S}$ and melittin Biochim Biophys Acta 1989;983(2):135-141. doi:10.1016/00052736(89)90226-5.

[28] Koshy AS, Anila L, Vijayalakshmi NR. Impact of certain flavonoids on lipid profiles - potential action of Garcinia cambogia flavonoids. Phytother Res 2001;15(5):395-400. doi:10.1002/ptr.725.

[29] Mackeen MM, Mooi LY, Amran M, Mat N, Lajis NH, Ali AM. Noncytotoxic and antitumour-promoting activities of Garcinia acid esters from Garcinia atroviridis Griff. ex T. Anders (Guttiferae). Evid Based Complement Alternat Med 2012;2012:1-5. doi:10.1155/2012/829814.

[30] EPA. U.S. High production volume (HPV) chemical challenge program assessment plan for acetic acid and salts category. 2001;1-20.

[31] Blasiak J, Trzeciak A, Kowalik J. Curcumin damages DNA in human gastric mucosa cells and lymphocytes. J Environ Pathol Toxicol Oncol 1999;18(4):271-276. doi:10.1002/(SICI)1520-6866(1999)19:1<19::AID$\mathrm{TCM} 3>3.0 . \mathrm{CO} ; 2-\mathrm{H}$

[32] Sánchez-Lamar A, Fonseca G, Fuentes JL, Cozzi R, Cundari E, Fiore M, et al. Assessment of the genotoxic risk of Punica granatum L. (Punicaceae) whole fruit extracts. J Ethnopharmacol 2008;115(3):416422. doi:10.1016/j.jep.2007.10.011.

[33] Carocho M, Ferreira ICFR. A review on antioxidants, prooxidants and related controversy: Natural and synthetic compounds, screening and analysis methodologies and future perspectives. Food Chem Toxicol 2013;51:15-25. doi:10.1016/j.fct.2012.09.021.

[34] Jiang Z, Hu Z, Zeng L, Lu W, Zhang H, Li T, et al. The role of the Golgi apparatus in oxidative stress: is this organelle less significant than mitochondria?. Free Radic Biol Med 2011;50(8):907-917. doi:10.1016/j. freeradbiomed.2011.01.011.

[35] Kurz T, Eaton JW, Brunk UT. Redox activity within the lysosomal compartment: implications for aging and apoptosis. Antioxid Redox Signal 2010;13(4):511-523. doi:10.1089/ars.2009.3005.

[36] Oluyemi KA, Omotuyi IO, Jimoh OR, Adesanya OA, Saalu CL, Josiah SJ. Erythropoietic and anti-obesity effects of Garcinia cambogia (bitter kola) in Wistar rats. Biotechnol Appl Biochem 2007;46(1):69-72. doi:10.1042/BA20060105. 